\title{
Bulbar Signs in Normal Population
}

\author{
KS Lim, YC Hew, HK Lau, TS Lim, CT Tan
}

\begin{abstract}
Background and Objectives: There is lack of published data on bulbar signs among the healthy population. This study aims to determine the range of normality of bulbar signs particularly among the elderly. Methods: Systemic examination of bulbar signs was carried out according to a predetermined protocol on a cohort of young and elderly healthy subjects. Results: A total of 206 subjects were recruited in the study, 104 young adults with mean age of 20 years, and 102 elderly with mean age of 73 years. Uvula deviation was seen in $28(26.9 \%)$ young subjects and $22(21.6 \%)$ elderly. Irregular tongue border was seen in 17 subjects, unilateral in 4 subjects. Fourteen (6.8\%) subjects had deviation on tongue protrusion. Occasional tremor of tongue on protrusion is common in both young and old. Persistent (severe) tongue tremor on protrusion was seen in $18.6 \%$ of the elderly, and $4.8 \%$ of the young. None of the subjects had tremor of tongue at rest. In gag reflex, absence of gagging response was common in elderly, seen in two thirds of the subjects on stimulation of the posterior pharyngeal wall. However, all the subjects had uvular movement. Habituation or suppression of gagging response was seen in close to $90 \%$ of young males. Conclusion: There is wide range of normality in bulbar signs in normal population, particularly among the elderly.
\end{abstract}

RÉSUMÉ: Signes bulbaires dans la population normale. Contexte et objectifs : Il n'existe pas de données dans la littérature sur la présence de signes bulbaires dans la population en bonne santé. Le but de cette étude était de déterminer les limites de la normale concernant la présence de signes bulbaires, particulièrement chez les gens âgés. Méthodes : Nous avons examiné systématiquement une cohorte de sujets jeunes et de sujets âgés en bonne santé pour détecter des signes bulbaires selon un protocole prédéterminé. Résultats : Nous avons recruté 206 sujets, soit 104 jeunes adultes dont l'âge moyen était de 20 ans et 102 sujets âgés dont l'âge moyen était de 73 ans. Une déviation de la luette a été observée chez 28 sujets jeunes $(26,9 \%)$ et chez 22 sujets âgés $(21,6 \%)$; le bord de la langue était irrégulier chez 17 sujets et c'était unilatéral chez $4 ; 14$ sujets $(6,8 \%)$ avaient une déviation de la langue à la protraction ; un tremblement occasionnel de la langue à la protraction est fréquent tant chez les sujets jeunes que chez les sujets âgés. Un tremblement persistant (sévère) de la langue à la protraction a été observé chez 18,6\% des sujets âgés et chez $2,8 \%$ des sujets jeunes. Aucun des sujets ne présentait de tremblement de la langue au repos. L'évaluation du réflexe pharyngé a mis en évidence une absence fréquente de réponse nauséeuse chez les sujets âgés, soit chez les deux tiers de ces sujets, lors de la stimulation du pharynx postérieur. Cependant, la luette était mobile chez tous les sujets. Un phénomène d'échappement ou une suppression de la réponse nauséeuse a été observé chez près de $90 \%$ des hommes jeunes. Conclusion : Il existe une grande plage de normalité dans la présence de signes bulbaires dans la population normale, particulièrement chez les gens âgés.

Can. J. Neurol. Sci. 2009; 36: 60-64

Bulbar is defined in Dorland's Medical Dictionary as "pertaining to or involving the medulla oblongata". Thus, examination of the bulbar system pertains to examination of the function of lower cranial nerves originated from the medulla oblongata, i.e. 9 th to 12 th cranial nerves.

Asymmetry of structure (atrophy), persistent movement at rest (fasciculation and tremor), with movement (deviation and tremor), and absence or impaired reflex activities are the usual clinical observations interpreted as indicative of pathology in clinical examination of the bulbar system. There is considerable range of normality in the function of the bulbar structure particularly among the elderly in the healthy population. For example, gag is defined as to retch, or strive to vomit. Absence of gagging response was often noticed in healthy subjects, especially in the elderly. Previous studies revealed an incidence of absent gagging response ranging from $13-37 \%$ in the normal

From the Division of Neurology, Faculty of Medicine, University of Malaya, Malaysia. Received July 23, 2008. Final Revisions Submitted September 9, 2008. Correspondence to: Lim Kheng-Seang, Neurology Laboratory, 5U, University of Malaya Medical Centre, 59100 Kuala Lumpur, Malaysia. 
population. ${ }^{1-2}$ Leder et al reported that $86 \%(12 / 14)$ of those without gagging response had normal soft palate movement. Thus, active soft palate movement without gagging response to stimulation is common among the healthy population.

The aim of this study was to determine the range of normality in bulbar function among healthy young and elderly populations using a pre-determined protocol of systemic examination.

\section{METHODS}

A standardized bulbar examination method was designed and was performed in a group of healthy volunteers who were young adult medical students and elderly volunteers aged 60 and above. Those with past history of neurological disease or radiotherapy to the bulbar region were excluded from the study. The assessors first went through a preliminary study involving more than a 100 subjects to familiarize themselves with the methods of examination. For the study proper, each abnormality noted was counter-checked by another trained assessor and recorded using video or photograph to be reassessed by a neurologist. Informed consent was obtained prior to participation in the study.

a) Uvula position and soft palate movement

Upon opening of the mouth, the uvula position was observed with tongue depressed at rest and after saying 'Aah', documented as normal or deviated. The uvula is considered to be deviated if it is drawn to either side at rest and after saying 'Aah', without palatal movement. The degree of uvula deviation is graded as mild if angle of deviation $<30^{\circ}$ and severe if $\geq 30^{\circ}$, as shown in Figure 1.

Soft palate movement on each side was observed when the person said 'Aah' with the tongue depressed with spatula, graded as normal, reduced or absent.

b) Tongue inspection and power assessment

The following observations were made with the tongue lying on the floor of the mouth: fasciculation, asymmetry in size, central furrowing, increased grooving of the tongue and uneven/irregular border (either unilateral or bilateral); documented as present or absent. Tongue fasciculation is defined as small local involuntary contractions, or twitching of groups of tongue muscle, visible through mucus membrane..$^{3-4}$ Fasciculation requires observation of more than two twitches in the same muscle.

Tongue tremor, defined as rhythmic oscillation of the tongue, was observed when the tongue was lying on the floor of the mouth and at maximal tongue protrusion. Tongue tremor was graded as absent, occasional or persistent. Observation was also made of the co-existence of postural hand tremor.

The subjects were then asked to push the tongue hard against each cheek from inside. The strength of the tongue was graded as normal, reduced when it was weaker than the opposite side, and absent. The subjects were asked to protrude the tongue centrally to the maximum; graded as present or absent, to the left or right.

c) Gag reflex examination

Gag reflex examination is performed by touching the posterior pharyngeal wall, posterior one third of the tongue and the surface of soft palate at each side with a wooden stick after the tongue is pressed down with spatula. Both the reflex contraction of the soft palate and the presence of gagging/ retching response were inspected and graded as absent, palatal movement only or palatal movement with gagging/ retching response (gagging response). The reflexes in these sites were tested separately in the beginning and the end of the whole procedure to avoid possibility of habituation. Presence of sensation to touch was documented as present, reduced as compared to the other side or absent.

\section{d) Habituation of gagging response}

A subgroup of young adults with prominent gagging/retching response in gag reflex examination was investigated for habituation of the gagging response. The gag reflex examination with posterior pharyngeal wall stimulation was repeated with the subjects being asked to suppress the response voluntarily. The repeated gag reflex was documented as absent, uvula movement only or gagging/retching response.

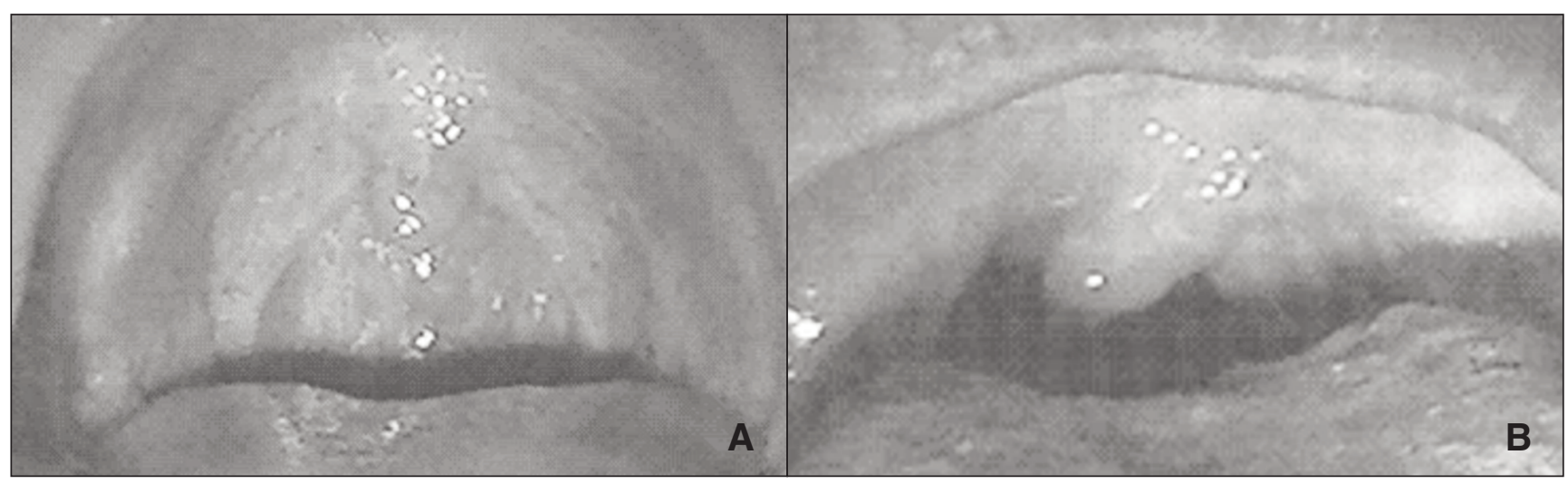

Figure 1: (A) This picture showed mild uvula deviation, as compared to (B) severe uvula deviation when saying 'Aah'. 
e) Speech assessment and ability to cough

The subjects were asked to repeat the word 'Hippopotamus', documented as normal, nasal or spastic. The presence of hoarseness was noted. The subjects were then asked to cough explosively, and documented as able or unable.

\section{f) Sternomastoid examination}

The muscle bulk of the sternomastoid on each side was observed, and documented as atrophied or normal. The strength of sternomastoid muscle was assessed by asking the subjects to flex the neck to 30 degrees against resistance and to turn the head to one side against resistance, comparing the strength both sides. ${ }^{5}$ The strength was graded according to MRC at 0-5.

\section{Statistical analysis}

The data was analyzed using SPSS program. Chi squared (chi2) tests were used in the analysis of proportions, and twotailed Student's t test was used in the analysis of continuous variables. Statistical significance implied $\mathrm{p}<0.05$ unless otherwise stated.

\section{Results}

Of the 206 study subjects, 104 were young and 102 elderly. There were 120 males and 86 females, with no differences between the young and elderly groups. Of the ethnic composition, there were $64(61.5 \%)$ Chinese, $34(32.7 \%)$ Malays, and $6(5.8 \%)$ Indians among the young subjects, and 54 $(52.9 \%)$ Chinese, 38 (37.3\%) Malays, and 10 (9.8\%) Indians among the elderly subjects. The mean age was 20.0 years (range $18-23$ ) in young and 73.0 years (range 60-86 years) in the elderly.

\section{Examination of uvula, soft palate, and tongue}

Uvula deviation was found in 28 (26.9\%) young subjects and $22(21.6 \%)$ elderly, the difference was not statistically significant. Left uvula deviation was found in 21 subjects and right in 29 subjects. Severe uvula deviation was noted in 9 $(32.1 \%)$ young and $4(18.2 \%)$ elderly subjects; the difference was also not statistically significant (Table 1). Soft palate movement of all the subjects was normal.

On tongue inspection, there was only one elderly volunteer with tongue asymmetry. No fasciculation, central furrowing and increased grooving was observed. Unilateral irregular tongue border was found in 4 young subjects and bilateral irregular tongue border in 13 subjects ( 8 in elderly and 5 in young subjects). There was no statistically significant difference between the young and elderly groups (Table 1$)$.

On tongue protrusion, $14(6.8 \%)$ subjects were found to have deviation; more common among the elderly $(12,11.8 \%)$ as compared to the young $(2,1.9 \%)$. The difference was statistically significant $(\mathrm{p}=0.005)$. Tongue deviation was equally common on both sides. There was no correlation between tongue deviation and uneven border ( $\mathrm{OR}=0.846,95 \% \mathrm{CI}$ : 0.104-6.892). None of the subjects had tongue weakness.

Twenty six young subjects (20 males and 6 females) were asked to perform up-down, in-out and left-right repetitive movements. The mean duration for one turn of the movement was 0.59 second for up-down, 0.63 second for in-out and 0.69 for left-right. The mean duration for left-right movement was longer in males, with no difference between the sexes in up-down and in-out movements.

None of the subjects had tongue tremor at rest. On tongue protrusion, $81(39.3 \%)$ subjects; $38(36.5 \%)$ young and 43 $(42.2 \%)$ elderly had tremor. There was no statistically significant difference between the young and elderly groups. There were 57 subjects (33 young and 24 elderly subjects) with occasional tremor and 24 with persistent tremor (5 young and 19 elderly). Persistent tongue tremor was more common in the elderly, as compared with the young subjects $(44.2 \%$ vs $13.2 \%, \mathrm{p}=0.002)$. The mean age for the elderly with absent, occasional and persistent tongue tremor was $63.3,69.8$ and 72.4 years respectively. However, these were not statistically significant.

Eighty seven subjects $(42.2 \%)$ were found to have postural hand tremor. The incidence of hand tremor was higher in the elderly $(n=54,52.9 \%)$, as compared to the young $(n=33,31.7 \%)$. The difference was statistically significant $(\mathrm{p}=0.002)$. There was strong correlation between tongue tremor and hand tremor with OR 5.07, 95\% CI 2.77-9.27 (Table 2).

\section{Gag reflex examination}

Pharyngeal sensation was present in all subjects. Voluntary palatal elevation was normal in all subjects. None of the subjects had asymmetry of response between left and right. Among the three sites of stimulation in both young and elderly subjects, posterior pharyngeal wall was the most sensitive site to provoke gagging: $91.3 \%, 50.3 \%$ and $18.3 \%$ for posterior pharyngeal wall, soft palate and posterior tongue in the young adults respectively. In comparison between young and elderly subjects, the incidence of gagging response was higher in young subjects in all the three sites of stimulation as shown in Table 3; all differences were

Table 1: Comparison of uvula and tongue observations between the young and elderly subjects

\begin{tabular}{l|c|c|c}
\hline & $\begin{array}{c}\text { Young, N=104 } \\
\mathrm{n}(\%)\end{array}$ & $\begin{array}{c}\text { Elderly, N=102 } \\
\mathrm{n}(\%)\end{array}$ & P value \\
\hline Uvula Deviation & $28(26.9)$ & $22(21.6)$ & $\mathrm{NS}$ \\
\hline $\begin{array}{l}\text { Severe Uvula } \\
\text { Deviation }\end{array}$ & $9(8.7)$ & $4(3.9)$ & $\mathrm{NS}$ \\
\hline $\begin{array}{l}\text { Irregular Tongue } \\
\text { Border }\end{array}$ & $9(8.7)$ & $8(7.8)$ & $\mathrm{NS}$ \\
\hline Tongue Tremor & $38(36.5)$ & $43(42.2)$ & $\mathrm{NS}$ \\
\hline Severe Tongue & $5(4.8)$ & $19(18.6)$ & 0.002 \\
Tremor & & & \\
\hline Tongue Deviation & $2(1.9)$ & $12(11.8)$ & 0.005 \\
\hline
\end{tabular}

NS: not significant 
Table 2: Correlation of tongue and hand tremor

\begin{tabular}{l|l|c|c|c}
\hline \multicolumn{2}{c|}{} & \multicolumn{2}{c|}{ Tongue Tremor } & \multirow{2}{*}{ Total } \\
\hline \multicolumn{2}{c|}{} & Yes (\%) & No (\%) & \\
\hline \multirow{2}{*}{\begin{tabular}{l} 
Tremor \\
\cline { 3 - 4 }
\end{tabular}} & Yes & $53(25.7)$ & $34(16.5)$ & $87(42.2)$ \\
\cline { 2 - 4 } & No & $28(13.6)$ & $91(44.2)$ & $119(57.8)$ \\
\hline \multicolumn{2}{c|}{ Total } & $81(39.3)$ & $125(60.7)$ & $206(100)$ \\
\hline
\end{tabular}

Table 3: Comparison of responses in gag reflex examination between the young and elderly subjects in three different sites of stimulation

\begin{tabular}{|c|c|c|c|c|c|}
\hline \multirow[t]{2}{*}{$\begin{array}{l}\text { Site of } \\
\text { stimulation }\end{array}$} & \multicolumn{2}{|c|}{$\begin{array}{l}\text { Young, n (\%) } \\
\qquad N=104\end{array}$} & \multicolumn{2}{|c|}{$\begin{array}{l}\text { Elderly, n (\%) } \\
\qquad N=102\end{array}$} & $P$ value \\
\hline & $\begin{array}{c}\text { Palatal } \\
\text { movement } \\
\text { only }\end{array}$ & $\begin{array}{l}\text { Gagging } \\
\text { response* }\end{array}$ & $\begin{array}{c}\text { Palatal } \\
\text { movement } \\
\text { only }\end{array}$ & $\begin{array}{l}\text { Gagging } \\
\text { response* }\end{array}$ & \\
\hline Posterior tongue & $85(81.7)$ & $19(18.3)$ & $94(92.2)$ & $8(7.8)$ & 0.027 \\
\hline Soft palate & $52(50.0)$ & $52(50.0)$ & $75(73.5)$ & $27(26.5)$ & 0.001 \\
\hline Pharyngeal wall & $9(8.7)$ & $95(91.3)$ & $67(65.7)$ & $35(34.3)$ & $<0.001$ \\
\hline
\end{tabular}

*All subjects with gagging response had palatal movement as well

3/16 (19\%) of males versus 14/15 (93.3\%) showing gagging response on repeat testing.

\section{Speech and sternomastoid examination}

On speech assessment, all subjects were normal, with none having hoarseness. All subjects were also able to cough explosively. Sternomastoid examination for power of neck flexion and head turning were also normal for all subjects.

\section{DisCuSSION}

Our study shows a wide range of normality in bulbar signs in normal population, particularly among the elderly. As stated by Campbell, trivial deviations of the midline raphe are not of clinical significance. ${ }^{6}$ However, severe uvula deviation with symmetrical elevation of the palatal muscles was observed in this series as well, with the prevalence as high as $8.7 \%$ of young subjects and $3.9 \%$ of elderly. Therefore, severe uvula deviation without soft palate movement abnormalities should also not be interpreted as indicative of pathology. There is no statistically significant difference in the prevalence of uvula deviation among groups. This implied that uvula deviation might be congenital.

We have also found irregular tongue border to occur in healthy population: close to $10 \%$ of both young and elderly subjects, about half being unilateral and bilateral. Tongue deviation on protrusion was more common in the elderly subjects, close to $12 \%$ of the elderly versus $2 \%$ in the young. There was no correlation between tongue deviation with uneven tongue border. Therefore, tongue deviation without other abnormalities of the tongue or other neurological deficits should be regarded as normal during clinical examination.

The prevalence of occasional (mild) tongue tremor on protrusion is high with no difference between elderly and young groups, (42.2\% and $36.5 \%$ respectively). Tongue tremor was correlated with postural hand tremor. None of the patients had symptoms that could be attributed to the tongue tremor. Occasional tremor of tongue on protrusion should be regarded as a normal finding.
Figure 2: Habituation of gag reflex: Frequency of response in second gag reflex examination according to sex distribution. 
As for persistent (severe) tongue tremor on protrusion, the prevalence is high among the elderly in our study, seen in close to two fifths of those studied. Among our elderly subjects, the mean age of those with persistent (severe) tongue tremor is 72.4 years, higher than those without tongue tremor (63.3 years), or with occasional tongue tremor (69.8 years). Persistent (severe) tongue tremor is also seen in close to $5 \%$ of the young adults. The tremor is postural in nature because it only presents at tongue protrusion. None of the patients had symptoms that could be attributed to the tongue tremor. According to the diagnostic criteria for essential tremor by the Movement Disorder Society and International Tremor Foundation ${ }^{7}$, tongue tremor is classified as possible essential tremor type II. Louis et al suggested that the prevalence of essential tremor increases with age. ${ }^{8}$ The correlation with age of persistent (severe) tongue tremor in our subjects is consistent with the concept that it is part of essential tremor.

Estimates of the frequency of essential tremor differ more than 100-fold, due largely to sampling limitations and to differences in diagnostic criteria. Most studies estimate the prevalence as between 40 and 400 per 10,000 persons, but the range is very wide (from 0.8 to 2200 per 10,000 ) ${ }^{9-10}$ Our study shows that the prevalence of essential tremor may even be higher, with close to $20 \%$ of the elderly population and $5 \%$ of young adults having tongue tremor.

Essential tremor has been said to be most frequently seen in hands (95\% of cases), followed by the head (34\%), legs $(20 \%)$, voice $(12 \%)$, and face $(5 \%) .{ }^{11}$ Head involvement was more common in the elderly. ${ }^{12}$ Our study shows that tongue tremor is common, its frequency may be close to that of hand tremor.

The long term outcome of subjects with persistent (severe) tongue tremor is unknown.

None of our patients had tremor of tongue at rest. Tongue tremor occurring at rest should be regarded as abnormal.

As for gag reflex, our study shows that palatal movement is a stable reflex seen in both young and old, and asymmetry of palatal movement on phonation or pharyngeal stimulation is a reliable clinical sign as none of our subjects have asymmetry of palatal movement. Gagging response is, however, much more age dependent, seen in about $90 \%$ of the young and occurring in only about a third of the elderly subjects even during posterior wall stimulation. This corresponds to the study by Davies et al, who showed that gagging response was absent in $43 \%$ of the elderly, and $26 \%$ of the young subjects. ${ }^{1}$ We also demonstrated the lower gagging response rate on stimulation of the soft palate and posterior tongue, and habituation of the reflex, particularly among the young males.

In view of the large proportion of normal population who have palatal movement only without gagging response, the terms "pharyngeal reflex" or "palatal reflex" should perhaps replace "gag reflex", as being more accurate.

\section{ACKNOWLEDGEMENTS}

The authors thank all the volunteers in this study.

\section{REFERENCES}

1. Leder SB. Gag reflex and dysphagia. Head Neck. 1996;18(2): 138-41.

2. Davies AD, Kidd D, Stone SP, MacMahon J. Pharyngeal sensation and gag reflex in healthy subjects. Lancet. 1995;345(8948): 487-8.

3. Campbell WW. Dejong's the neurologic examination. 6th ed. United States of America, Philadelphia: Lippincott Williams \& Wilkins; 2005. p. 273

4. Anderson DM. Dorland's Illustrated Medical Discionary. 30th ed. Philadelphia: Saunders; 2003. p.676.

5. Talley JN. Clinical examination: a systematic guide to physical diagnosis. 5th ed. Sydney: Churchill Livingstone; 2006.

6. Campbell WW. Dejong's the neurologic examination. 6th ed. United States of America: Lippincott Williams \& Wilkins; 2005. p. 254.

7. Deuschl G, Bain P, Brin M. Consensus statement of the movement disorder society on tremor. Ad hoc scientific committee. Mov Disord. 1998;13:22-3.

8. Louis ED, Marder K, Cote L. Differences in the prevalence of essential tremor among elderly African Americans, whites, and Hispanics in northern Manhattan, NY. Arch Neurol. 1995;52: 1201-5.

9. Louis ED, Ottman R, Hauser WA. How common is the most common adult movement disorder? Estimates of the prevalence of essential tremor throughout the world. Mov Disord. 1998;13: 5-10.

10. Findley LJ. Epidemiology and genetics of essential tremor. Neurology. 2000;54 Suppl 4:S8-13.

11. Elble RJ. Diagnostic criteria for essential tremor and differential diagnosis. Neurology. 2000;54 Suppl 4:S2-6.

12. Lou JS, Jankovic J. Essential tremor: clinical correlates in 350 patients. Neurology. 1991;41:234-8. 